\title{
28 Research Square \\ Friction Stir Processing of Hybrid Al-Si Alloy Metal Matrix Composite
}

\section{Vipin Sharma}

Sagar Institute of Research and Technology

Yogesh Dewang

Lakshmi Narain College of Technology

Pardeep Kumar Nagpal

I K Gujral Punjab Technical University: IK Gujral Punjab Technical University Jalandhar

Suresh Kumar ( $\nabla$ skumartom@gmail.com )

DRDO TBRL: DRDO Terminal Ballistics Research Laboratory

\section{Research Article}

Keywords: Friction stir processing, Composites, MMC, Mechanical Properties, Al-Si alloy

Posted Date: May 25th, 2021

DOI: https://doi.org/10.21203/rs.3.rs-521330/v1

License: (c) (1) This work is licensed under a Creative Commons Attribution 4.0 International License. Read Full License 


\section{Abstract}

Metal matrix composites are an important class of material that is developing rapidly to fulfil the diversified engineering requirements. The metal matrix composites are attractive owing to superior properties as compared to monolithic material. Their properties are dependent on various factors and fabrication techniques. The metal matrix composites are associated with several issues which hinder their full potential. In the present study friction stir processing is applied on the metal matrix composite as a post-processing operation. The friction stir processing offers many advantages owing to the solidstate nature of the processing. Stir cast metal matrix composites are prepared by using zircon sand particles of $50 \mu \mathrm{m}$ in the matrix of LM13 aluminium alloy. The friction stir processing is applied on the metal matrix plates at a constant rotational speed and traverse speed of $1400 \mathrm{rpm}$ and $63 \mathrm{~mm} / \mathrm{min}$, respectively. Multiple passes of friction stir processing are applied to elucidate the effect of the number of passes on microstructural modification. Microstructural examination showed a significant improvement in eutectic silicon morphology and distribution of zircon sand particles. A more than 5 times reduction as compared to the initial size was observed in the zircon sand particles after four passes of friction stir processing. The processed metal matrix composite also exhibits improvement in tensile strength and hardness.

\section{Introduction:}

Metal matrix composites (MMCs) are extensively used in various engineering applications due to ease in manufacturing and significant enhancement in properties [1, 2]. MMCs are manufactured by different routes and the resulting characteristics of MMCs are dependent on the production route $[3,4]$.The stir casting method is commonly used for the production of MMCs due to ease of operation, economic aspect and mass production [5].

There are some issues and challenges in the manufacturing of MMCs that significantly impair the properties to great extent [6-9]. The poor interfacial bonding and agglomeration of reinforcement particles is an important issue to achieve the full potential of MMCs [8]. A good interfacial bonding between the reinforcement and the matrix is necessarily required in MMCs because the load transfer between the matrix and the reinforcement relationship is controlled by the bonding characteristics. Therefore, the bonding characteristics of a composite dictate its properties and performance [10,11]. The interfacial bonding mainly depends on the degree or extent of wettability of reinforcement particles with the melt. Reinforcement particles wettability with the melt mainly depends on the surface energy of the matrix and the reinforcement, and also on the surface condition of the particles such as the amount of oxidation or contamination $[7,12]$. Most ceramics are not wetted or are poorly wetted by molten metals. Porosity is a major issue in MMCs manufacturing that deteriorates mechanical properties as it reduces the load-bearing area and acts as a crack nucleation site $[13,14]$. The presence of porosity at the particle/matrix interface causes debonding of particles from the matrix under very low stresses which reduces the possibility of load transfer to the particle and subsequently decreases in strength [13-15]. Agglomeration of reinforced particles is an unavoidable issue in MMCs. The agglomeration of particles 
also induces microstructural inhomogeneity that creates stress gradients in MMCs and thus deteriorates mechanical properties $[16,17]$.

Microstructural phages and intermetallic compounds that are formed during the production of MMC can significantly affect mechanical properties [18]. In Al-Si alloys, the eutectic silicon is present as a coarser phase in the matrix of MMCs which is a deleterious morphology and causes failure emanated from this phase. Dendritic growth typically occurs in aluminum-based MMCs that affect the mechanical properties [19]. Secondary processing or post-processing of MMCs is required to distribute the reinforcement particles homogeneously in the matrix and to improve the mechanical properties [20,21]. Traditionally various post-processing techniques such as extrusion, rolling, uniform channel angular pressure, selective laser melting, high pressure torsion, accumulation roll bonding, etc. have been used to process MMCs [20-22]. Nonetheless, friction stir processing (FSP) of MMCs emerged as an effective strategy in postprocessing of MMCs [23-25]. The FSP is a prominent severe plastic deformation technique in which a simultaneously rotating and traversing tool processes the material with a high strain rate. The grain size refinement in the processed material occurred due to dynamic recrystallisation $[25,26]$. It provides a synergistic effect of extrusion, forging, stirring, and severe plastic deformation, which can easily circumvent issues in MMCs manufactured by traditional techniques.

Several studies have been reported on the post-processing of MMCs by the FSP. Kurtyka et al. [27] demonstrated that after FSP the microstructural heterogeneity of SiC/A339 MMC was transformed into homogeneity. The FSPed MMC exhibited an increase in compressive strength by 40\% and hardness by $\sim 30 \%$ as compared to cast MMC. Huang et al. [28] reported an increase in yield strength, ultimate tensile strength and elongation of FSPed CNT/Mg-6Zn cast composite. The improvement in mechanical properties was attributed to combined strengthening contributions of grain refinement, load transfer and Orowan mechanism. They also found that grain size reduction in composite is more as compared to FSPed base alloy due to restriction imposed by CNTs in the grain boundaries migration. Yang et al. [29] investigated the effect of the FSP on $\mathrm{Al}_{2} \mathrm{O}_{3} / \mathrm{AA} 2024 \mathrm{MMC}$ cold sprayed coating and found that corrosion resistance was increased after two passes of FSP. However, after four passes of FSP the corrosion resistance decreased due to deteriorated interfaces of the inside coatings.

The FSP of MMCs resulted in microstructural refinement and homogeneous distribution of second phase particles. It can be concluded that FSP reinforcement of MMCS is a better strategy for uniform distribution of particles, reduction in the size of reinforcement, grain refinement, break-up of dendritic microstructure and elimination of porosity. In the present work, stir casted Al-Si (LM13) alloy based hybrid MMCs are post-processed by FSP to study the effect of microstructural modification on mechanical properties. The effect of multiple passes of FSP on microstructural modification and its correlation with mechanical properties is also investigated.

\section{Materials And Methods:}


In this work, MMCs were prepared by LM13 (Al-Si) alloy and 15 wt. \% zircon sand particles (ZrSiO4) of average $40 \mu \mathrm{m}$ size using stir casting technique. The composition of LM13 alloy is provided in table1.The process for fabrication of metal-matrix composites by stir casting consists of melting LM13 alloy in graphite clay bonded crucible at a temperature of $750^{\circ} \mathrm{C}$.

\begin{tabular}{|llllllllll|}
\hline \multicolumn{1}{|c|}{ Table-1 } \\
\hline Si & Cu & Fe & Mg & Mn & Zn & Ti & Ni & Al \\
\hline 11.7 & 1.2 & 0.28 & 0.9 & 0.4 & 0.2 & 0.02 & 0.9 & Balance \\
\hline
\end{tabular}

After melting of alloy, the reinforcement particles of zircon sand were mixed in the melt by a hopper arrangement and stirring of the melt is done by rotating graphite stirrer at $600 \mathrm{rpm}$. The stirring of melt was continued for 10 minutes to ensure proper mixing of reinforcement particles in the melt. After stirring, the melt was solidified in a metallic mould to room temperature. Solidified MMC was cut in a plate of 120 $\times 60 \times 6 \mathrm{~mm}$ size for conducting FSP. The schematic of FSP is presented in Fig. 1. A hot die steel tool (60 HRC) with a shoulder of $20 \mathrm{~mm}$ diameter and cylindrical pin of $4 \mathrm{~mm}$ length with $4 \mathrm{~mm}$ diameter as shown in Fig. 2 was used to process the MMCs. One pass, two passes and four passes of FSP with $100 \%$ overlapping was applied on the MMC. The FSP of the plates was carried out at the tool rotational and traverse speed of $1400 \mathrm{rpm}$ and $63 \mathrm{~mm} / \mathrm{min}$, respectively.

For the characterization of the MMC, a thin slice was cut from the stir cast composite and friction stir processed (FSPed) in the form of a plate.Metallographic probe samples were prepared using polishing grade emery paper and polished by the slurry of alumina powder in distilled water. Etching of prepared samples is done by modified Poulton's reagent $\left(40 \mathrm{~mL} \mathrm{HNO}_{3}, 30 \mathrm{~mL} \mathrm{HCl}, 12 \mathrm{~g} \mathrm{CrO}_{3}, 2.5 \mathrm{~mL} \mathrm{HF}, 42.5 \mathrm{~mL}\right.$ $\mathrm{H}_{2} \mathrm{O}$ ) for 10 seconds. Microstructural investigation of samples was carried out using LEICA DMI 5000M optical microscope.

The hardness of the samples was measured by Vickers's micro hardness tester (Omnitech MVH II, India) with a $200 \mathrm{gf}$ load and dwell time of 15 seconds. Tensile tests were conducted on a universal testing machine (UTM) (TINIUS OLSEN, MODEL: H25K-S, 25 KN, UK). The flat shape tensile specimens were cut from the processed zone(Fig. 3) and tested with a cross head speed of $1 \mathrm{~mm} / \mathrm{min}$.

\section{Results And Discussion:}

\subsection{Microstructural}

The micrograph of as-cast MMC is shown in Fig. 4 (a). The distribution of zircon sand is not uniform and particle clusters are observed. In the matrix, the acicular morphology of silicon is distributed with intermetallic phases. The aspect ratio of acicular eutectic silicon in MMC is $\sim 3$. The reinforcement particle is surrounded by eutectic silicon. This eutectic silicon in the vicinity of the particle during 
solidification can change the matrix alloy chemistry and the region near the particle becomes rich in eutectic silicon. Particle-matrix interface is also affected by the arrangement of eutectic silicon in the vicinity of the particle. It is well evident that load is transferred from the matrix to the reinforcement particles and eutectic silicon-rich phases at the particle-matrix interface can affect the load transfer. The arrangement of eutectic silicon in the vicinity of the particle can be attributed to the fact that zircon particles are acting as an effective nucleation site for eutectic silicon.

After one pass of FSP, break-up of zircon sand particles and acicular silicon occurred as shown in Fig. 4 (b). Particle agglomeration and casting defects were eliminated in one pass of FSP. Casting porosity and voids are eliminated due to axial force and homogenous stirring during FSP. The matrix becomes uniform with the aspect ratio of eutectic silicon reduced to $\sim 1$ owing to high strain and stirring action imposed by the FSP. Grain size refinement also occurred due to dynamic recrystallization during FSP. The Particlematrix interface also showed the presence of nucleated eutectic silicon phases. Nonetheless, their thickness is reduced which suggests limited nucleation due to low-temperature processing. It can be concluded that one pass of FSP cannot effectively refine the microstructure of the MMC. However, after two passes of FSP the zircon sand particles size was decreased to below $30 \mu \mathrm{m}$ as that of $50 \mu \mathrm{m}$ in the MMC (Fig. 4c). The eutectic silicon and primary silicon was also refined to a greater extent in the processed zone. Repeated deformation occurred in the second pass of FSP resulted in break-up of zircon sand and silicon.

The more significant change in microstructure and distribution of zircon sand particles was observed after four passes of FSP as shown in Fig. 4 (d). The zircon sand particles size was decreased to less than $10 \mu \mathrm{m}$ which is about five times the reduction of initial particle size. Similarly, eutectic silicon size is even decreased to submicron size. The acicular eutectic silicon typically observed in Al-Si alloys are equiaxed after FSP. This acicular eutectic is responsible for the early fracture of Al-Si alloys. The distribution of zircon sand particles was also uniform as compared to one and two passes of FSP. Four passes of FSP imposes repeated intense plastic deformation which reduces the size of zircon sand particles. After FSP the interface becomes more compacted without pores and discontinuity. The solid nature of processing and high amount of strain resulted in superior interfacial bonding.

\subsection{Micro-hardness}

Microhardness of MMC and FSPedMMC is shown in Fig. 5. The microhardness of MMC increases after one pass of FSP. The increase of hardness can be attributed to the uniform particle distribution, microstructural refinement and elimination of porosity. The microstructural investigation showed that casting defects, porosities and agglomeration of particles are eliminated during FSP. After two passes of FSP hardness improved due to the size reduction and uniform distribution of zircon sand particles. Four passes of FSP causes further improvement in hardness due to break up of silicon and size reduction of zircon sand particles. Moreover, uniform distribution of zircon sand particles after four passes of FSP also contribute to increasing hardness. It can be concluded that hardness increases with an increase in the number of passes of FSP. 


\subsection{Tensile Strength}

The tensile strength of the MMC and FSPed MMC is shown in Fig. 6. The MMC exhibits low tensile strength and ductility. The tensile strength of MMC was found to be $60 \mathrm{MPa}$ and elongation was below $1 \%$. The lower strength of MMC was attributed to the agglomeration of particles, porosity, dendritic branches and eutectic silicon morphology. The porosity and acicular silicon could easily initiate the void formation and subsequently fracture. After one pass of FSP, the strength improves and elongation was increased above $1 \%$. Microstructural modification causes an improvement in strength and elongation. Strength further improves after two passes of FSP due to the size reduction and uniform distribution of zircon sand particles. After four passes of FSP, the strength increases to $116 \mathrm{MPa}$ and four times improvement in elongation as compared to non-processed MMC. Size reduction of zircon sand, grain refinement and break up of silicon are main contributors to the improved strength. It was concluded that after four passes of FSP the tensile strength was increased to nearly two times as compared to unprocessed composite.

\section{Conclusions:}

The zircon sand reinforced LM13 MMCs was subjected to FSP at constant tool rotation and traverse speed. Multiple passes of FSP was applied to achieve the homogenous particle distribution in the matrix.The following are main conclusion of the present study:

1. Intense stirring action of the FSP break-up the eutectic silicon and distributes it homogeneously in the matrix. The intermetallic phases are also fragmented with the elimination of porosity.

2. Microstructural modification of composite depends on the number of passes. As the number of passes increases, grain refining increases and the size of the zircon sand particle decreases.

3. Nearly five times the size of zircon sand decreased from $50 \mu \mathrm{m}$ to $10 \mu \mathrm{m}$ after four passes of the FSP.

4. Mechanical properties also increase with the increase in the number of FSP passes. Strength and hardness increases after four passes of friction stir processing. After four passes of the FSP, there was an almost twofold improvement in tensile strength and a fourfold improvement in elongation.

\section{Declarations}

\section{Ethics approval}

Not applicable

\section{Consent to participate}

All the authors in this investigation voluntarily agree to participate in this research study. 


\section{Consent for publication}

All the authors in this investigation give the permission to the publisher to publish the Work if accepted.

\section{Availability of data and materials}

The datasets generated during and/or analysed during the current study are available on request from the corresponding author.

\section{Competing interests}

The authors declare that they have no conflict of interest.

\section{Funding}

No funds, grants, or other support was received.

\section{Author contributions}

Conceptualization: [Suresh Kumar]

Methodology: [Vipin Sharma, Yogesh Dewang]

Formal analysis and investigation: [Vipin Sharma, Pardeep Kumar Nagpal],

Writing - original draft preparation: [Vipin Sharma, Yogesh Dewang, Suresh Kumar];

Writing - review and editing: [Vipin Sharma, Suresh Kumar]

\section{Acknowledgements}

Not applicable

\section{Disclosure of potential conflicts of interest}

Not applicable

\section{Research involving Human Participants and/or Animals}




\section{Informed consent}

Not applicable

\section{References}

1. Sakthivelu, S., Sethusundaram, P.P., Ravichandran, M., Meiganamoorthy, M., (2021) Experimental Investigation and Analysis of Properties and Dry Sliding Wear Behavior of Al -Fe-Si Alloy Matrix Composites. Silicon 13:1285-1294.

2. SeyedPourmand, N., Asgharzadeh, H. (2020) Aluminum matrix composites reinforced with graphene: a review on production, microstructure, and properties. Critical Reviews in Solid State and Materials Sciences 45(4): 289-337.

3. Mortensen, A., \&Llorca, J. (2010) Metal matrix composites. Annual review of materials research 40, 243-270.

4. Zhou, M.Y.; Ren, L.B.; Fan, L.L.; Zhang, Y.W.X.; Lu, T.H.; Quan, G.F.; Gupta, M. (2020) Progress in research on hybrid metal matrix composites. Journal of Alloys and Compounds 155274.

5. Sharma, V; Kumar, S; Pandey, O.P. (2012) Correlation of Reinforced Ceramicparticle's Nature and Size with Microstructure and Wear Behavior of Al-Si Alloy Composite. Advanced Materials Research 585:564-568.

6. Kumar, Suresh; Sharma, Anju; Arora, Rama; Pandey, O.P. (2019). The microstructure and wear behaviour of garnet particle reinforced Al matrix composites. Journal of Materials Research and Technology 8 (6), 5443-5455.

7. Kumar, S., Singh, R., Hashmi, M. S. J. (2020) Metal matrix composite: a methodological review. Advances in Materials and Processing Technologies, 6(1), 13-24.

8. Manohar, G., Pandey, K. M., Maity, S. R. (2021) Effect of sintering mechanisms on mechanical properties of $A A 7075 / B_{4} C$ composite fabricated by powder metallurgy techniques. Ceramics International 47(11): 15147-15154.

9. Yang, Z., Fan, J., Liu, Y., Yang, Z., Kang, Y., Nie, J. (2021) Effect of combination variation of particle and matrix on the damage evolution and mechanical properties of particle reinforced metal matrix composites. Materials Science and Engineering: A 806:140804.

10. Xiong, B., Liu, K., Xiong, W., Wu, X., Sun, J. (2020) Strengthening effect induced by interfacial reaction in graphenenanoplatelets reinforced aluminum matrix composites. Journal of Alloys and Compounds 845: 156282.

11. Kar, C., Surekha, B. (2021) Characterisation of aluminium metal matrix composites reinforced with titanium carbide and red mud. Materials Research Innovations 25(2): 67-75. 
12. Mousavian, R. T., Damadi, S. R., Khosroshahi, R. A., Brabazon, D., Mohammadpour, M. (2015) A comparison study of applying metallic coating on SiC particles for manufacturing of cast aluminium matrix composites. The International Journal of Advanced Manufacturing Technology 81(1):433444.

13. Podymova, N. B., Kalashnikov, I. E., Bolotova, L. K., Kobeleva, L. I. (2019) Laser-ultrasonic nondestructive evaluation of porosity in particulate reinforced metal-matrix composites. Ultrasonics 99, 105959.

14. Tekmen, C., Ozdemir, I., Cocen, U., Onel, K. (2003) The mechanical response of Al-Si-Mg/SiCp composite: influence of porosity. Materials Science and Engineering: A, 360(1-2):365-371.

15. Tosun, G., Kurt, M. (2019) The porosity, microstructure, and hardness of Al-Mg composites reinforced with micro particle $\mathrm{SiC} / \mathrm{Al}_{2} \mathrm{O}_{3}$ produced using powder metallurgy. Composites Part $\mathrm{B}$ : Engineering, 174:106965.

16. Yang, N., Boselli, J., \& Sinclair, I. (2001) Simulation and quantitative assessment of homogeneous and inhomogeneous particle distributions in particulate metal matrix composites. Journal of microscopy 201(2): 189-200.

17. Aldas, K., \& Mat, M. D. (2005) Experimental and theoretical analysis of particle distribution in particulate metal matrix composites. Journal of materials processing technology 160(3): 289-295.

18. Sharma, V., Kumar, S., Panwar, R. S., Pandey, O. P. (2012). Microstructural and wear behavior of dual reinforced particle (DRP) aluminum alloy composite. Journal of materials science 47(18): 66336646.

19. Zhang, Q., Sun, D., Pan, S., Zhu, M. (2020). Microporosity formation and dendrite growth during solidification of aluminum alloys: Modeling and experiment. International Journal of Heat and Mass Transfer 146: 118838.

20. Sabirov, I., Kolednik, O., Valiev, R. Z., Pippan, R. (2005) Equal channel angular pressing of metal matrix composites: effect on particle distribution and fracture toughness. Acta Materialia 53(18): 4919-4930.

21. Sercombe, T. B., Li, X. (2016) Selective laser melting of aluminium and aluminium metal matrix composites. Materials Technology 31(2):77-85.

22. Bachmaier, A., Pippan, R. (2013) Generation of metallic nanocomposites by severe plastic deformation. International materials reviews 58(1): 41-62.

23. Sharma, V., Singla, Y., Gupta, Y., Raghuwanshi, J. (2018) Post-processing of metal matrix composites by friction stir processing. In AIP Conference Proceedings 1953(1) 090062).

24. Tewari, A., Spowart, J. E., Gokhale, A. M., Mishra, R. S., Miracle, D. B. (2006) Characterization of the effects of friction stir processing on microstructural changes in DRA composites. Materials Science and Engineering: A 428(1-2): 80-90.

25. Liu, Z. Y., Xiao, B. L., Wang, W. G., Ma, Z. Y. (2012) Singly dispersed carbon nanotube/aluminum composites fabricated by powder metallurgy combined with friction stir processing. Carbon $50(5)$ : 1843-1852. 
26. Sharma, V., Gupta, Y., Kumar, B. M., Prakash, U. (2016) Friction stir processing strategies for uniform distribution of reinforcement in a surface composite. Materials and Manufacturing Processes 31(10): 1384-1392.

27. Kurtyka, P., Rylko, N., Tokarski, T., Wójcicka, A., Pietras, A. (2015) Cast aluminium matrix composites modified with using FSP process Changing of the structure and mechanical properties. Composite structures 133: 959-967.

28. Huang, Y., Li, J., Wan, L., Meng, X., Xie, Y. (2018) Strengthening and toughening mechanisms of CNTs/Mg-6Zn composites via friction stir processing. Materials Science and Engineering: A 732: 205- 211.

29. Yang, K., Li, W., Xu, Y., Yang, X. (2019) Using friction stir processing to augment corrosion resistance of cold sprayed AA2024/ $\mathrm{Al}_{2} \mathrm{O}_{3}$ composite coatings. Journal of Alloys and Compounds 774: 12231232.

\section{Figures}

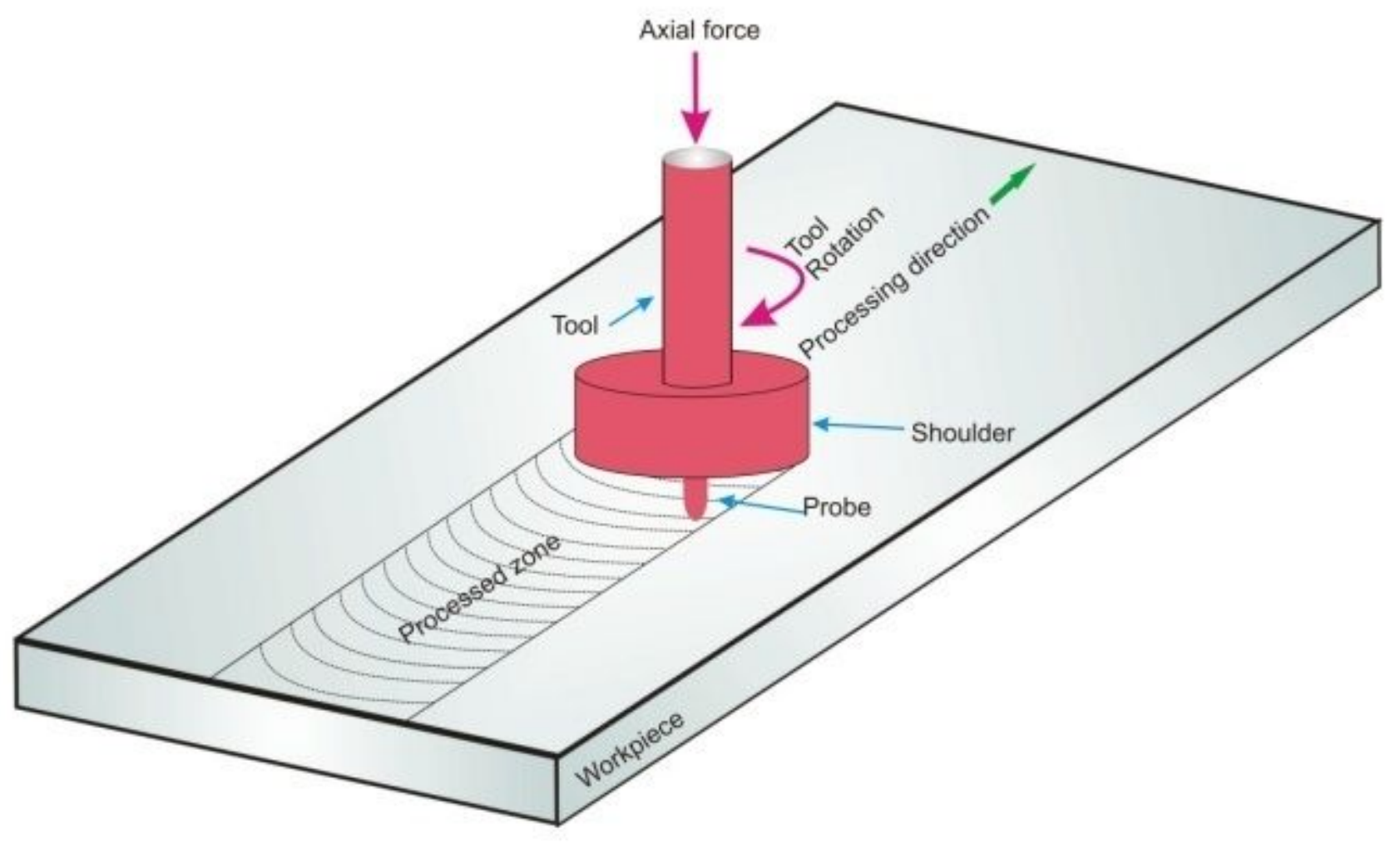

Figure 1

Schematic illustration of FSP. 

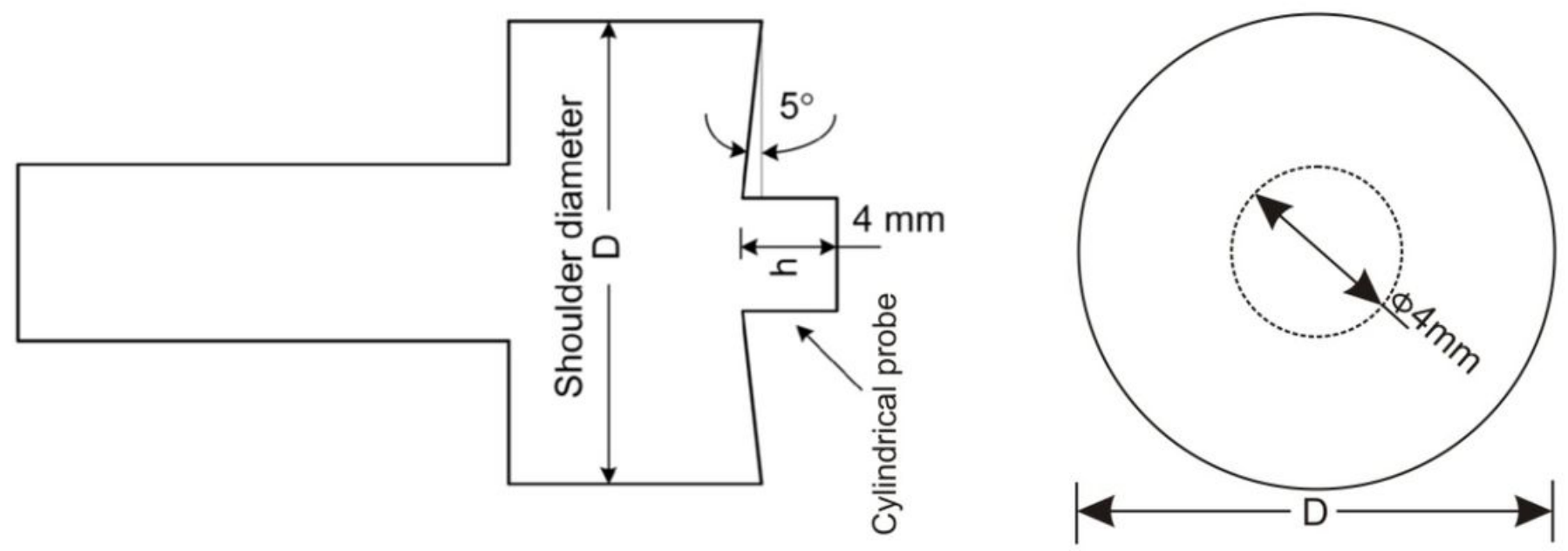

Figure 2

Tensile test specimen sliced from processed zone.

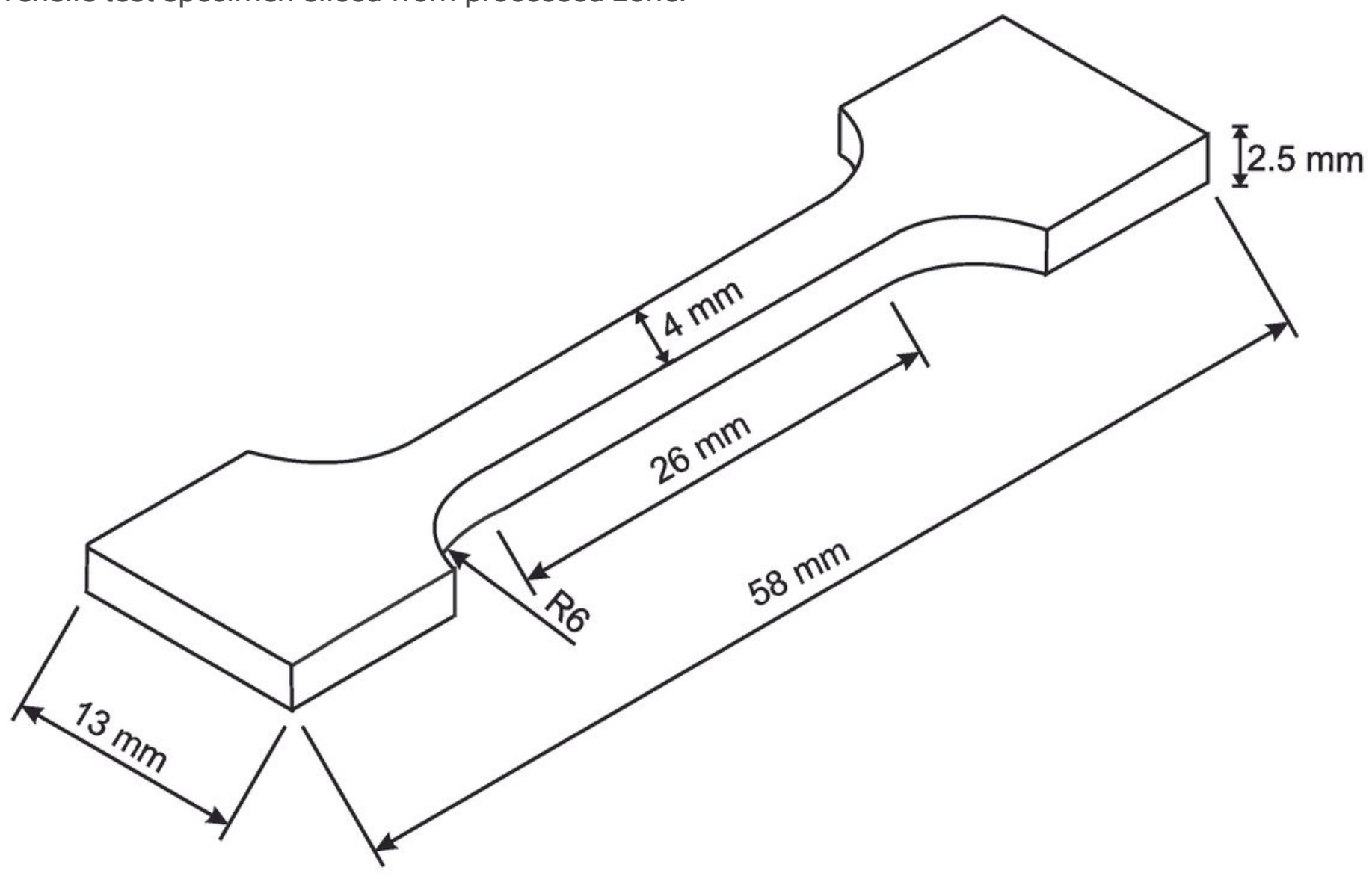

Figure 3

Tensile test specimen sliced from processed zone. 


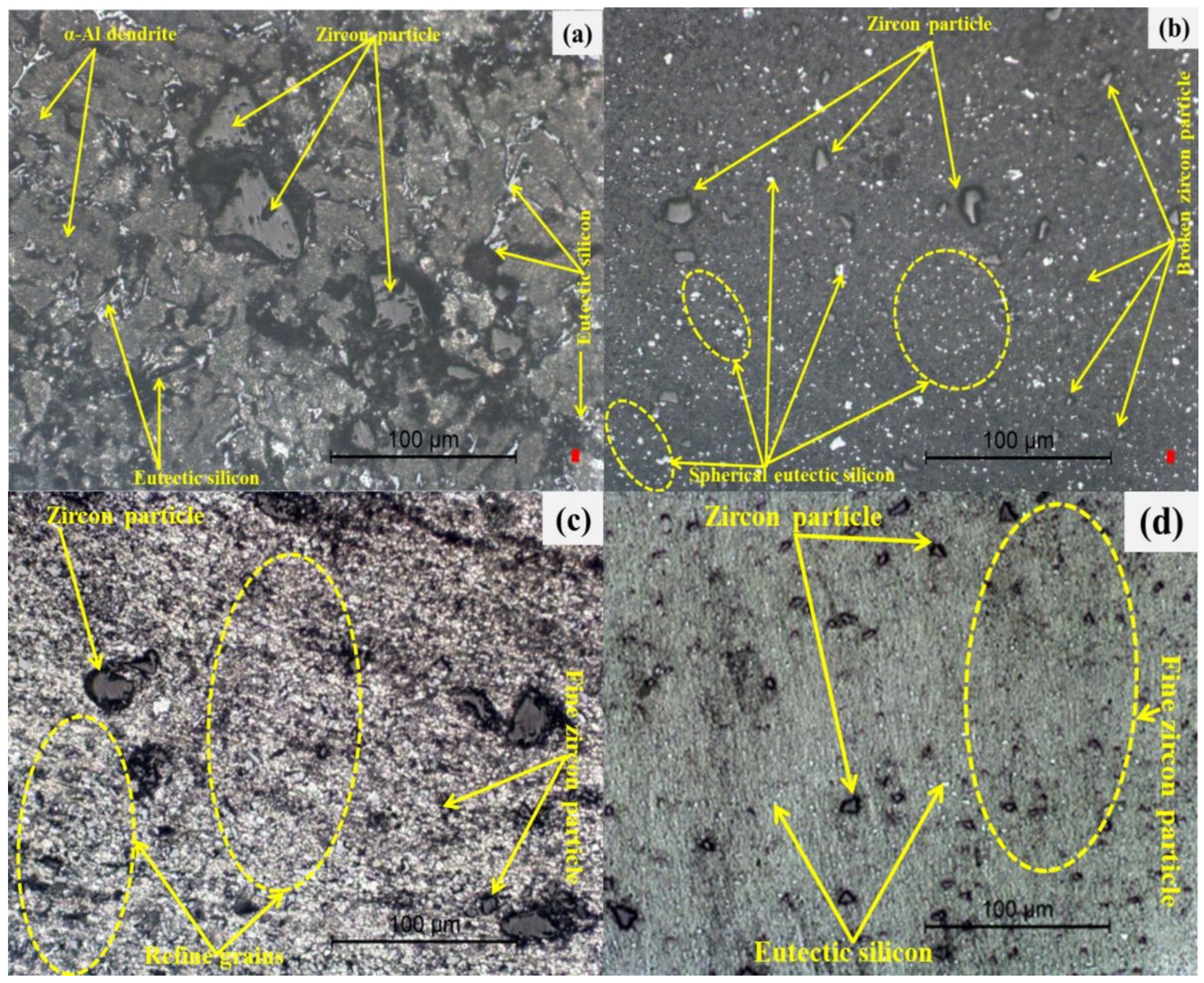

\section{Figure 4}

Optical micrograph of MMCs and FSPed MMCs (a) unprocessed MMC, (b) one pass FSPed MMC, (c) two pass FSPed MMC and (d) four pass FSPed MMC 


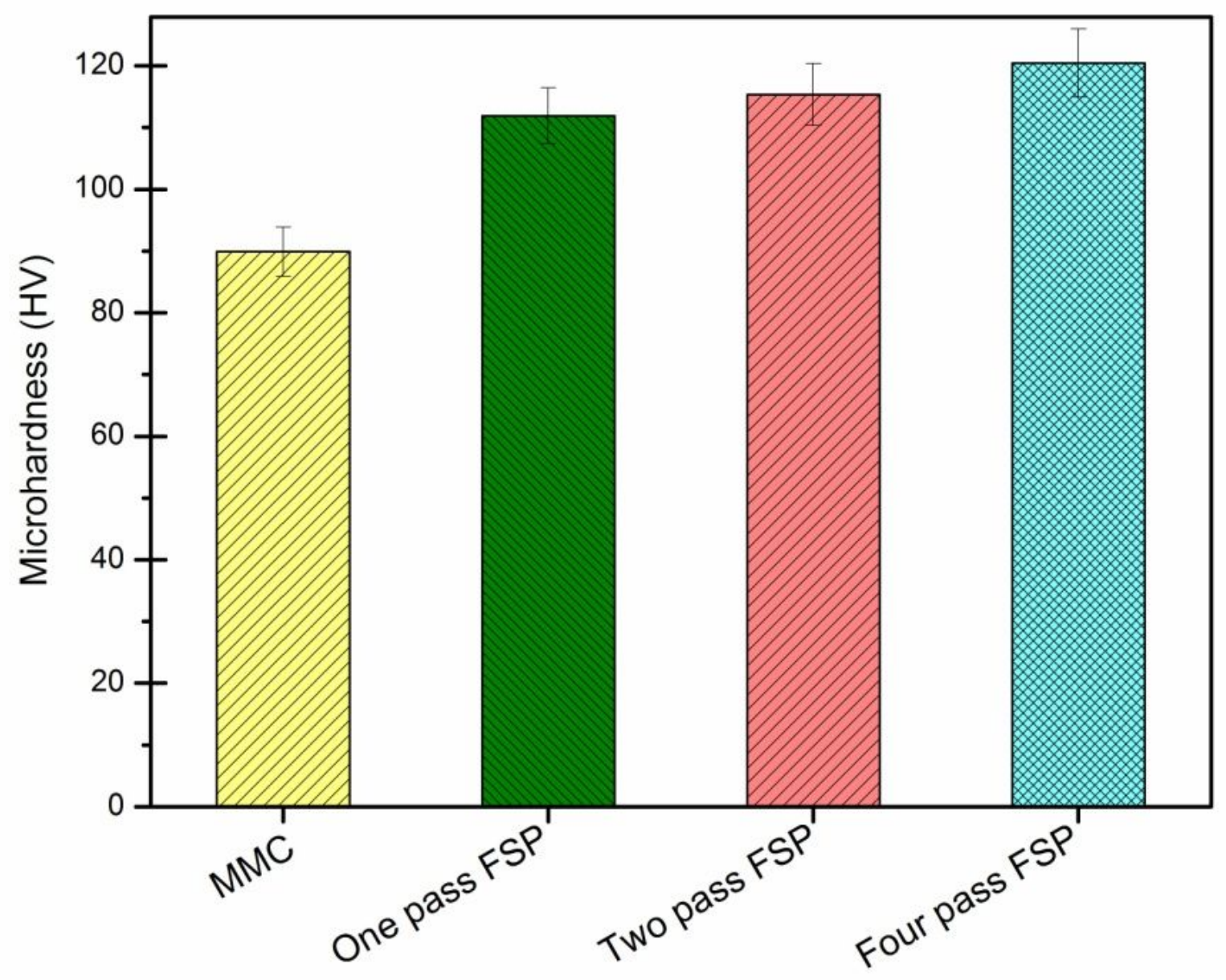

Figure 5

Microhardness of MMC and FSPed MMCs. 


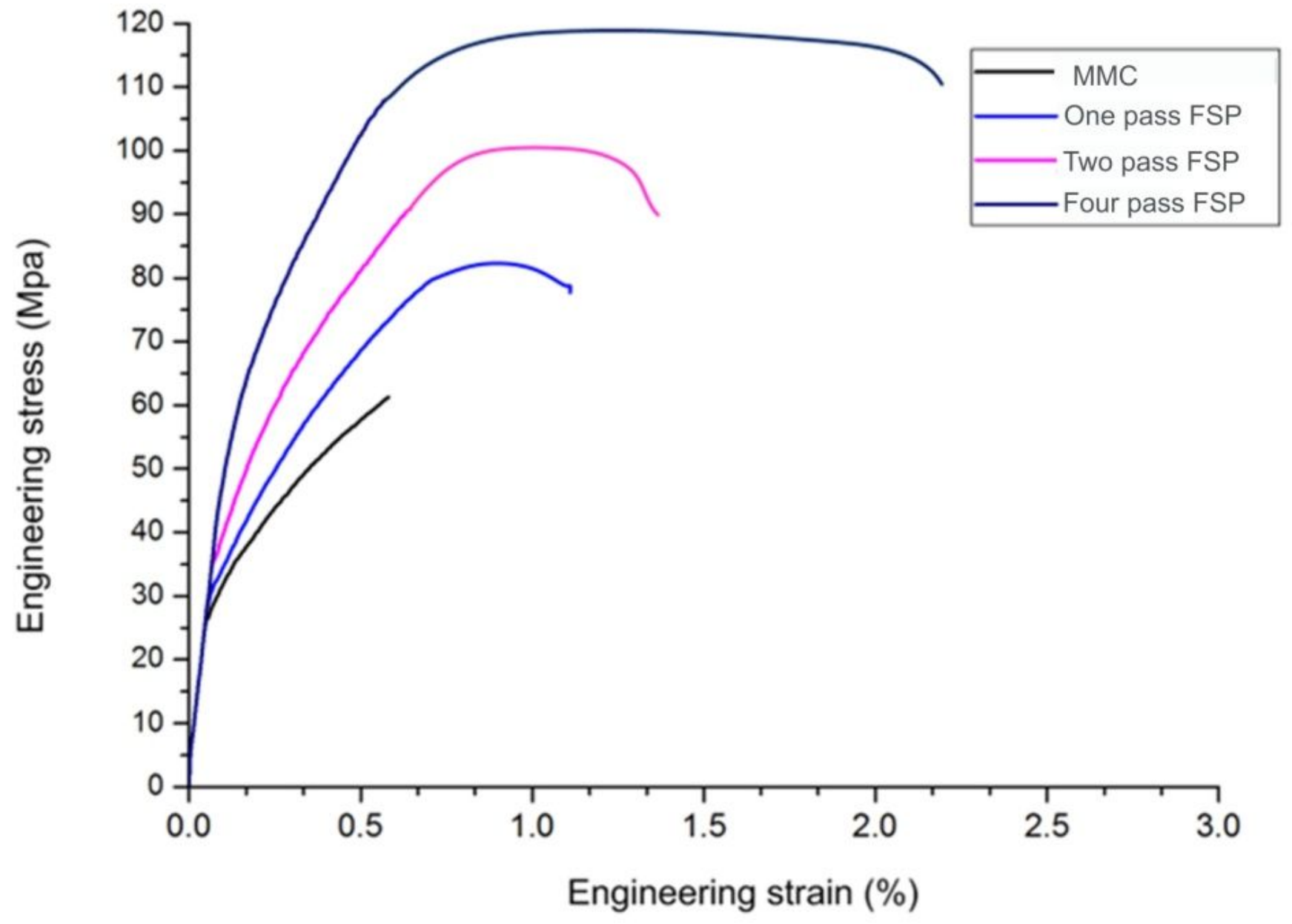

Figure 6

Engineering stress and strain curve for MMC and FSPed MMCs. 